\title{
Análise da temperatura aparente dos elementos da paisagem da microbacia Pedra do Índio em Alta Floresta-MT
}

\section{Analysis of the apparent temperature of the landscape elements of the Pedra do Índio microbasin in Alta Floresta-MT}

\author{
Charles Caioni ${ }^{1}$; Sandra Mara Alves da Silva Neves²; \\ Jakeline Santos Cochev ${ }^{3}$
}

\section{Resumo}

Tanto o desflorestamento quanto mudanças do uso da terra podem contribuir para a ocorrência de mudanças no clima local e regional. A redução da cobertura vegetal pode implicar na intensificação da seca, mediante ao aumento da temperatura aparente. Nesta conjectura, objetivou-se analisar a temperatura aparente da Microbacia Pedra do Índio (MPI), bem como sua associação com os diferentes usos/cobertura da terra. Para a elaboração dos mapas temáticos utilizou-se uma imagem LANDSAT (sensor TM), datada em 13/06/2010. A partir dos procedimentos de georeferenciamento, segmentação e classificação (executados no software SPRING) obteve-se das bandas 3, 4 e 5 os diferentes usos/cobertura, e da banda 6 a temperatura aparate. A pastagem consistiu no principal uso da terra na MPI, seguido da cobertura florestal. Houveram associações entre a temperatura aparente e os diferentes os usos da terra, ocorrendo os menores valores térmicos para ambientes hídricos e florestais, e maiores para áreas de pastagem plantada e solo exposto. Mediante a importância dos remanescentes florestais na perpetuação da disponibilidade hídrica da MPI, recomenda-se adoção de medidas que assegurem a proteção/conservação dessas áreas.

Palavras-chave: Recursos Hídricos. Análise Termal. Sensoriamento Remoto. Mudanças Microclimáticas.

\begin{abstract}
Both deforestation and land use changes can contribute to climate and regional changes. The reduction of the vegetal cover can imply in the intensification of the drought, by increasing the apparent temperature. In this conjecture, the objective was to analyze the apparent temperature of Pedra do Indio Microbacia (MPI), as well as its association with different uses/land cover. For the elaboration of the thematic maps a LANDSAT image (TM sensor) was used, dated 06/13/2010. From the georeferencing, segmentation and classification procedures (executed in the SPRING software) the bands 3, 4 and 5 obtained the different uses/coverage and the band 6 the aparate temperature. The pasture consisted of the main land use in MPI, followed by forest cover. There were associations between the apparent temperature and the different land uses, with the lowest thermal values for water and forest environments, and higher for areas of planted pasture and exposed soil. Due to the importance of forest remnants in perpetuating MPI's water availability, it is recommended to adopt measures that ensure the protection/conservation of these areas.
\end{abstract}

Keywords: Water Resources. Thermal Analysis. Remote Sensing. Microclimate Changes.

\footnotetext{
${ }^{1}$ Discente, Doutorado, PPGECB, UNEMAT, MT, Brasil; E-mail: charlescaioni@ hotmail.com

2 Profa. Dra. Departamento de Geografia, UNEMAT, MT, Brasil; E-mail: ssneves@ unemat.br

${ }^{3}$ Discente, Doutorado, PPG-BIONORTE, UNEMAT, MT, Brasil; E-mail: jackcochev@gmail.com
} 


\section{Introdução}

O clima é um fator determinante para o desenvolvimento de diversas atividades humanas, e o seu conhecimento proporciona o eficiente uso dos recursos naturais e não renováveis. A temperatura aparente e do ar está intimamente relacionada a quantidade de energia que chega da atmosfera, esta ao atingir a superfície é distribuída de forma não homogênea, variando de acordo com os diferentes elementos da paisagem (RANDOW et al., 2004). Para tanto, a conversão de áreas de vegetação natural por diferentes usos antrópico da terra deve ser feito de forma racional, visto que o mesmo pode contribuir para aumentos significativos da temperatura aparente (BLUNDEN; ARNDT, 2013; SILVÉRIO et al 2015). No sudeste amazônico, já se tem observado aumentos significativos da temperatura superfícial em unidades hidrográficas (CAIONI et al., 2017b), o que é preocupante, visto que o aumento exacerbado desta pode implicar na redução da disponibilidade hídrica.

O sensoriamento remoto pode ser considerado uma eficiente ferramenta no monitoramento da temperatura aparente em diferentes usos/cobertura da terra. Entende-se como sensoriamento remoto a arte e a ciência de obter informação sobre um objeto sem estar em contato físico direto com o mesmo (MOREIRA, 2003; ROSA, 2005). Para Nichol (1996) este mecanismo é promissor, visto que permite em tempo-sincronizado realizar análises termais de densas redes de dados.

Existem diversas técnicas de processamento que permitem a extração de informações a partir dos dados dos sensores remotos, sendo a classificação de imagens orbitais uma delas, pois possibilita a elaboração de mapeamentos de uso e ocupação da terra para posteriormente relacioná-los com as anomalias climáticas (LOARIE et al., 2011; CAIONI et al., 2018).

A intensificação do desmatamento na Amazônia remonta desde a década de 60. Segundo Becker (2001), a ocupação da Amazônia foi concebida como uma solução para as tensões sociais internas, como a modernização da agricultura no Nordeste e Sudeste. Conforme Souza (2006), entre 1960 e 1970 o desmatamento era reflexo de um modelo desenvolvimentista e de integração para a região Amazônica. Mas hoje, ele pode ser encarado como um reflexo da economia nacional (MACEDO et al., 2013). Em meio a este contexto encontra-se a Microbacia Pedra do Índio (MPI), que localizada no município de Alta Floresta/MT apresenta elevado nível de perda de sua cobertura florestal. O presente estudo objetivou em analisar a temperatura aparente da Microbacia Pedra do Índio, bem como sua associação com os diferentes usos/cobertura da terra.

\section{Material e Métodos}

\section{Área de estudo}

A MPI possui uma área de $5.360 \mathrm{ha}$. Localizada entre as coordenadas $56^{\circ} 30^{\prime}$ a $57^{\circ} 00^{\prime}$ de longitude $W$ e $9^{\circ} 00^{\prime}$ a $11^{\circ} 00^{\prime}$ de latitude $S$, a MPI pertence ao município de Alta Floresta, distante $830 \mathrm{~km}$ da capital, Cuiabá (Figura 1).

O município de Alta Floresta, possui uma população estimada em 50.189 habitantes (IBGE, 2018). O IDH-M (Índice de Desenvolvimento Humano) é de 0,714, abaixo do IDH do Estado, que é de 0,725 e do Brasil que é de 0,730 (IBGE, 2010). Suas principais atividades econômicas são a pecuária extensiva e a agricultura (CORRÊA et al., 2013).

Conforme a classificação Koppen atualizada por Alvares et al. (2013), o clima da região é tropical de monções (Am), com nítida estação seca. Sua precipitação fica entorno de $2200 \mathrm{~mm}$ (SOUZA et al 2013; ARAUJO et al., 2014), e sua temperatura média é de aproximadamente $26^{\circ} \mathrm{C}$ (CAIRES; DIAZ, 2002).

As bacias hidrográficas que compõem a região são formadas pelos rios Cristalino, Santa Helena, Teles Pires e Paranaíta (SOUZA, 2006), sendo em sua maioria recobertas pela Floresta Ombrófila Aberta, que se caracterizam por apresentar espécies vegetais de grande porte e elevado espaçamento entre os indivíduos.

O relevo da região pode ser dividido em quatro unidades geomorfológicas: Depressão Interplanáltica da Amazônia Meridional, Planaltos dos Apiacás-Sucunrudi, Planalto Dissecado da Amazônia e os Planaltos residuais do Norte de Mato Grosso (CAMARGO et al., 2010).

\section{Procedimentos metodológicos}

O trabalho foi desenvolvido a partir da geração de um Banco de Dados Geográficos-BDG utilizando o software Spring 4.3 (CÂMARA et al, 19960 disponível no sítio do Instituto Nacional de Pesquisas Espaciais-INPE.

Em seguida foi obtido no site do INPE uma imagem orbital da plataforma Landsat 5, (sensores Thematic MapperMT), referente a data de 13/06/2010, órbita/ponto 227/67.

As bandas 3, 4, 5 e 6 foram convertidas para o formato "Grib"no módulo IMPIMA 4.3, e posteriormente no SPRING passaram pelo registro (georreferenciamento) no modo tela-a-tela, onde utilizou-se a imagem ortorretificada GeoCover, disponibilizada no sitio da NASA (National Aeronautics and Space Administration). Utilizou-se as 
Figura 1: Localização da MPI no município de Alta Floresta/MT.

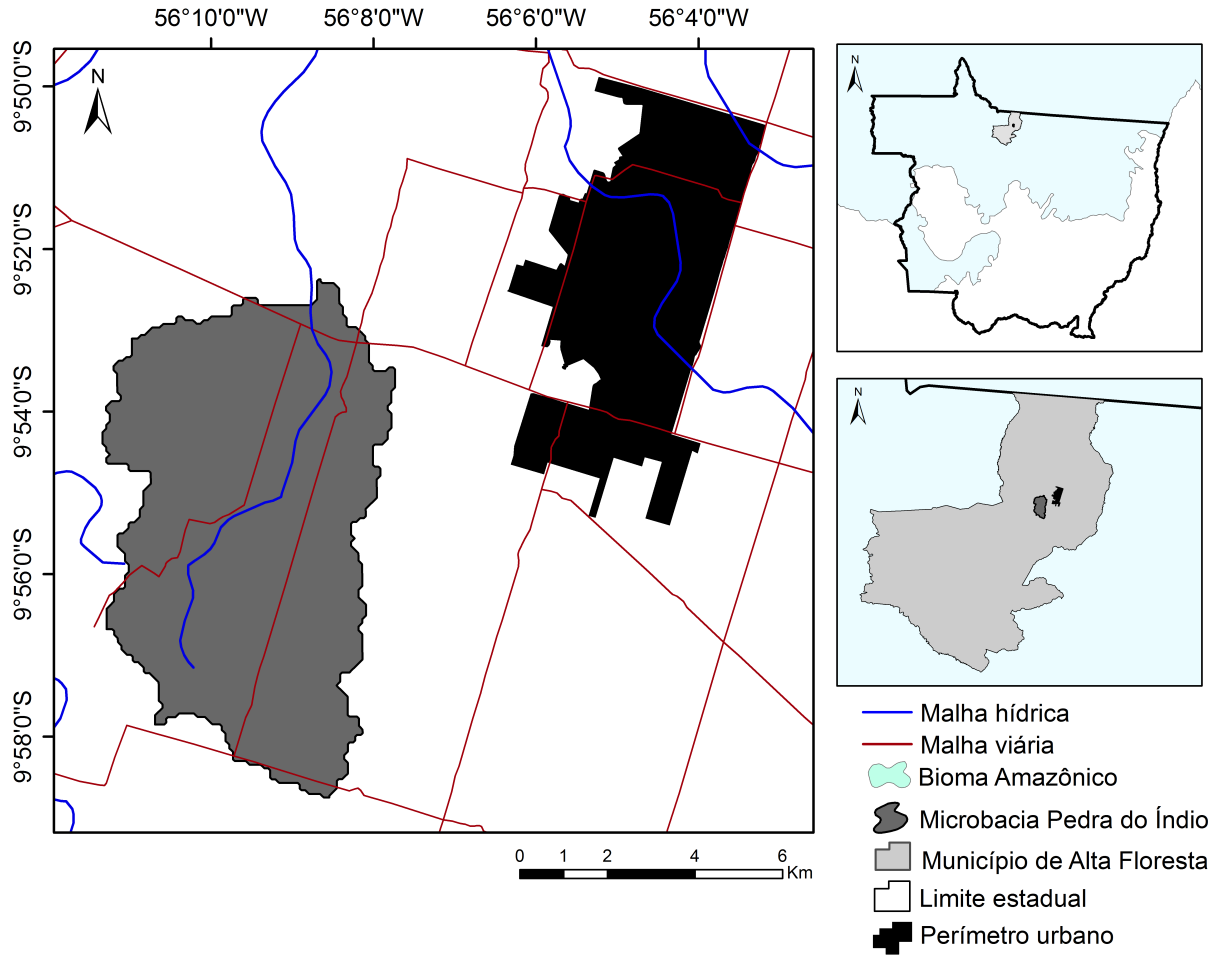

Fonte: autoria própria.

bandas 3, 4 e 5 para a geração do mapa de uso e cobertura da terra, e a banda 6 , relativa a faixa termal do espectro eletromagnético, para a elaboração do mapa da temperatura aparente.

Para a obtenção do mapa de uso/cobertura da terra aplicou-se nas bandas (3, 4 e 5) os procedimentos de recorte, segmentação e classificação, operacionalizados no SPRING 4.3. Na segmentação foi adotado o método de crescimento de regiões (distância Battacharrya) para agrupar os "pixels"adjacentes e semelhantes, gerando regiões homogêneas, com valores de limiares de similaridade 10 e área 10. O limiar de similaridade é a distância euclidiana máxima entre os centros espectrais de duas regiões e o limiar de área é o tamanho mínimo em pixel de uma região que se pretende delimitar.

Durante a classificação foram definidas as seguintes classes:

- Floresta: refere-se o domínio da Floresta Ombrófila Aberta, composta por palmeiras, cipós ou bambus, dependendo das feições fitoecológicas de floresta em função das características do relevo;

- Pastagem plantada: compreende as formações com extrato em que predomina a presença de espécies forrageiras, desprovidas ou não de indivíduos arbóreos em baixa densidade;

- Solo exposto: áreas de solos isentos de qualquer tipo de cobertura vegetal;

- Massa d' água: áreas ocupadas com água livre de vegetação, englobando os rios e lagos.

As terminologias e as descrições consideradas no mapeamento do uso da terra e cobertura vegetal seguiram a classificação fisionômico-ecológica da vegetação neotropical do projeto TerraClass (COUTINHO, 2013).

No programa ArcGis, versão 9.2 (ESRI, 2007), os erros de rotulação de classes foram corrigidos por meio da edição de polígonos, quando havia discordância entre os resultados da classificação e as informações obtidas nos trabalhos de campo e no mapeamento realizado pelo projeto TerraClass (COUTINHO, 2013).

No intuito de obtenção a temperatura aparente da banda 6, aplicou-se o processo de classificação não supervisionada por meio da ferramenta "segmentação", com agrupamento de pixels, considerando-se área de 2 pixel e similaridade de 2. A partir do arquivo gerado extraíram-se os atributos de cada polígono, identificando e gerando classes aleatórias de acordo com a tonalidade dos pixels da imagem. Em virtude do cálculo de temperatura ser feito a partir dos níveis de cinza da imagem, não se realizou o contraste da banda 6 , a fim de evitar possíveis alterações nos resultados.

Por meio da ferramenta leitura de pixels do SPRING, identificaram-se os níveis de cinza de cada região gerada 
no processo de segmentação. Para a conversão dos valores de cinza dos pixels da banda termal em índices de temperatura aparente aplicou-se a equação (1) (MALARET et al., 1985)

$$
T=209,831+0,834 D N-0,00133 D N 2,
$$

sendo:

$T=$ temperatura aparente (Kelvins) e $D N=$ número digital de cada pixel.

A conversão da temperatura de Kelvins para graus Celsius, foi realizada conforme equação (2).

$$
T_{c}=T_{k}-273,15
$$

onde:

$T_{c}=$ Temperatura em Celsius e $T_{k}=$ Temperatura em Kelvin.

Por meio dos valores térmicos, definiu-se 5 classes de temperatura, havendo associação de pseudo cores para as classes no mapa elaborado, para facilitar a leitura do produto. Contudo, não foi possível estabelecer intervalos fixos e idênticos, uma vez que cada região obteve níveis térmicos variados. A criação dos layouts do mapa foi feita no programa Arcgis, versão 9.2 (ESRI, 2007). A quantificação de cada classe foi realizada a partir da extensão Xtools.

\section{Resultados e Discussão}

A MPI em decorrência de seu posicionamento geográfico (próximo ao perímetro urbano), pode ser considerada estratégica no futuro abastecimento urbano/rural de Alta Floresta, contudo, a análise de uso da terra/cobertura revelou que aproximadamente 3523,97 ha $(64,74 \%)$ já se encontram desflorestados, sendo 3343,87 ha $(62,38 \%$ ) correspondentes apenas de pastagem plantada (Figura 2). Esses resultados são decorrentes da pecuária extensiva ser a principal atividade econômica na região (CORRÊA et al., 2013; CAIONI et al., 2017a). Nascimento (2012) expôs que essa atividade contribui para desmatamento na Amazônia, mediante a necessidade de conversão de extensas áreas de vegetação natural em pastagem plantada.

As áreas de floresta totalizaram 1773,37 ha $(33,09 \%)$, estando localizadas em sua maioria próximos ou ao entorno dos cursos hídricos (Áreas de Preservação Permanentes-APP). Conforme Brasil (2012), o componente arbóreo é essencial para a manutenção e proteção dos recursos hídricos e do fluxo gênico da fauna/flora. Uma explicação para a situação evidenciada é que os proprietários preservam de vegetação nativa apenas o que é prevista na Lei Complementar $n^{\circ} 412$ (MATO GROSSO,
2010), que delimita a proteção integral de 50 metros ao redor das nascentes e 30 metros ao entorno dos cursos hídricos.

A MPI demostrou que possui 62,66 ha $(1,17 \%)$ de massa d'água. Essa considerável área reforça a importância dessa unidade hídrica no abastecimento futuro da população urbana e rural do município.

As áreas de solo exposto totalizaram 180,10 ha $(3,36 \%)$. Este resultado pode ser decorrente da imagem utilizada compreender ao período da seca no munícipio. Assim, os elevados índices de degradação das pastagens vieram a apresentar características semelhantes às de solo exposto. Possivelmente, se outra análise for realizada utilizando imagem de data pertinente ao período chuvoso, estas áreas poderão ser classificadas como pastagens. A temperatura aparente oscilou ao longo de toda a MPI. Com mínimas de $22,4^{\circ} \mathrm{C}$ e máximas de $32,7^{\circ} \mathrm{C}$, a média ficou em torno de $28,2^{\circ} \mathrm{C}$ (Figura 3). Essa elevada média é decorrente de embora o mês de agosto pertencer à estação de inverno na região centro oeste, em alta floresta a precipitação é baixa, o que contribui para a secagem de vegetações. Conforme Nery e Carfan (2012), Região Centro-Oeste possui variações sazonais que definem pelo menos dois regimes de precipitação pluvial: um seco (junho, julho e agosto) e outro chuvoso (dezembro, janeiro e fevereiro).

A análise conjunta das figuras 2 e 3 possibilitou evidenciar a presença/ausência dos diferentes usos da terra, entre as classes de temperatura. Para a classe de $22,40^{\circ} \mathrm{C}$ a $25,50^{\circ} \mathrm{C}$ constatou-se forte presença de cursos hídricos e remanescentes florestais, isso porque, grande parte da energia incidente em ambientes aquáticos é gasto no processo de evaporação da água ( $2,45 \mathrm{MJ} / \mathrm{m}^{2}$ por milímetro). Callejas et al. (2011), em seu estudo também constatou que as massas d'água desempenham, assim como a vegetação, um importante papel no controle da estabilidade mesoclimática nas microbacias, uma vez que com pequenas variações térmicas todos os ambientes onde ocorreram grande presença deste elemento verifica-se amplitudes térmicas abaixo da média.

Estudo recente tem relevado que mediante a temperatura aparente na floresta pode ser resultante da junção entre temperatura do solo e do dossel, o sombreamento do solo (proporcionado pelas folhas) contribui ainda mais para menores valores térmicos. Conforme Randow et al. (2004) e Vourlitis et al. (2008) as raízes profundas das árvores permitem ainda a obtenção de água em camadas mais profundas do solo, levando a floresta a manter elevada taxa evapotranspiração mesmo em meses de elevado déficit hídrico. 
Figura 2: Usos da terra e cobertura vegetal na Microbacia Pedra do Índio/MT, em 13 junho de 2013.

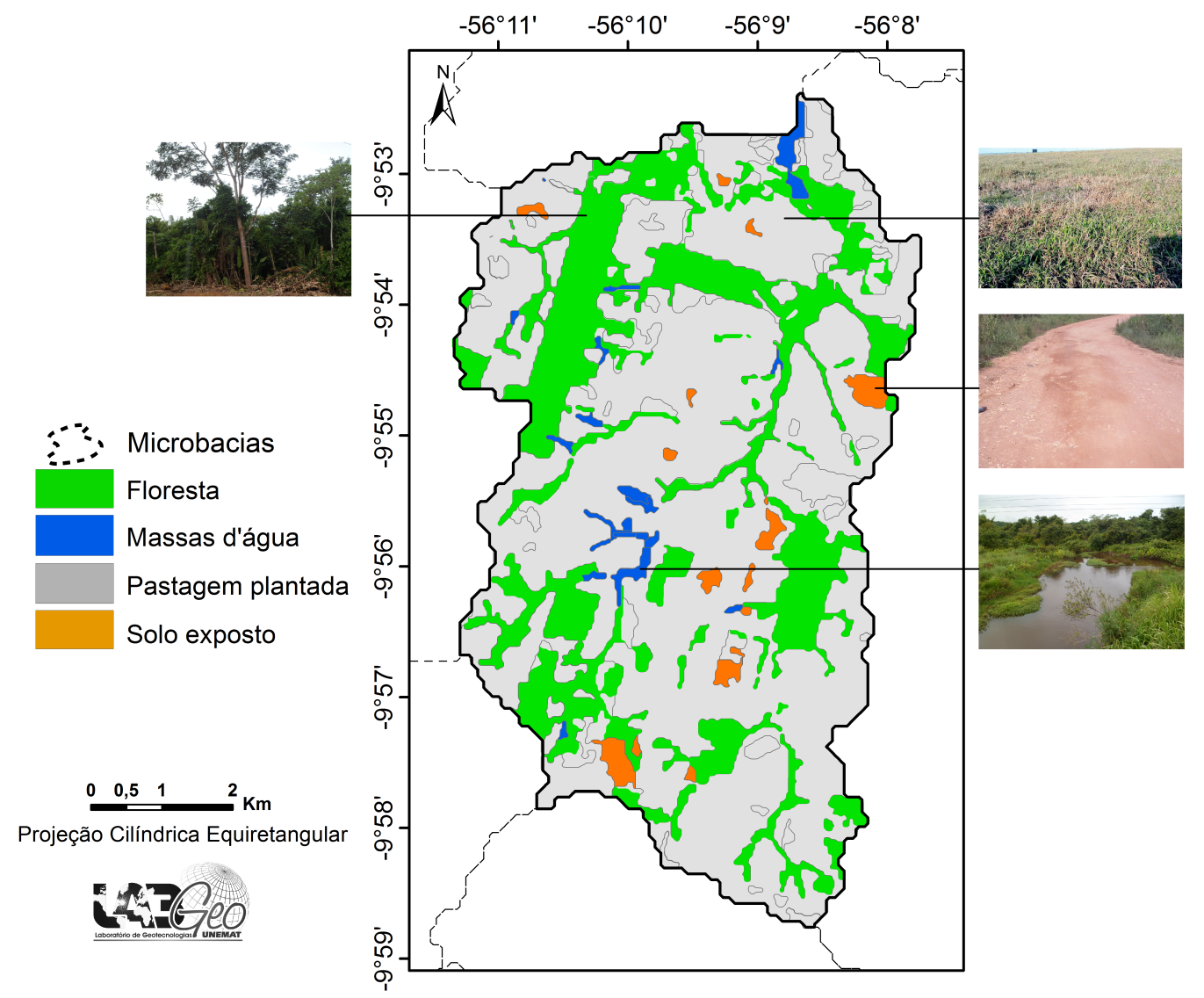

Fonte: autoria própria.

Oliveira et al. (2013) e Silvério et al. (2015), mencionam ainda que a quantidade de radiação solar que chega à superfície abaixo da copa é reduzida, uma vez que parte da radiação incidente é absorvida pelas folhas e outra fração é refletida de volta para a atmosfera. É esperado que entre 50 a $75 \%$ da radiação solar que incide sobre a floresta seja empregada no processo evapotranspiração (OMRAN et al.,2012). Sob tais condições, é possível afirmar que a vegetação funciona como um termorregulador microclimático devido às suas características físicas e morfológicas. As classes termais de $26,31^{\circ} \mathrm{C}$ a $27,80^{\circ} \mathrm{C}$ e de $27,81^{\circ} \mathrm{C}$ a $29,10^{\circ} \mathrm{C}$ ocorreram em sua maioria nas porções norte e sul da microbacia (Figura 3), onde encontram-se grandes extensões de pastagem plantada. Uma das possíveis explicações para esses valores, reside no processo de secagem da pastagem. Gramíneas por possuírem raízes pouco profundas, ficam limitadas a obterem água apenas nas primeiras camadas do solo, vindo assim a secarem e consequentemente a aumentarem a temperatura aparente ainda nos primeiros meses de estiagem das chuvas (PRIMAVESI et al. 2007).

No tocante a classe de maior amplitude térmica $\left(29,11^{\circ} \mathrm{C}\right.$ a $\left.32,70^{\circ} \mathrm{C}\right)$, constatou-se forte presença nesta de áreas de solo exposto. Este resultado corrobora com os de Silva e Santos (2007), que evidenciaram padrões semelhante para áreas de solos desnudos. Essas áreas tendem a exibir maiores temperaturas mediante a baixa capacidade de retenção de água, e consequentemente baixa taxa de evapotranspiração.

\section{Conclusões}

Constatou-se forte proximidade entre a temperatura aparente e os diferentes usos/cobertura da terra, evidenciando maiores temperaturas para ambientes com maior presença de solo exposto e pastagem. Para tanto, é possível presumir que a ação antrópica tem contribuído para o aumento da temperatura aparente ao longo de toda a microbacia, e que o aumento do desflorestamento pode colocar em risco a perpetuação da disponibilidade hídrica da unidade hidrográfica.

De modo geral, salienta-se a importância da preservação dos remanescentes florestais, visto o seu papel no controle microclimático da unidade hidrográfica estudada. 
Figura 3: Temperaturas aparente da Microbacia hidrográfica Pedra do Índio.

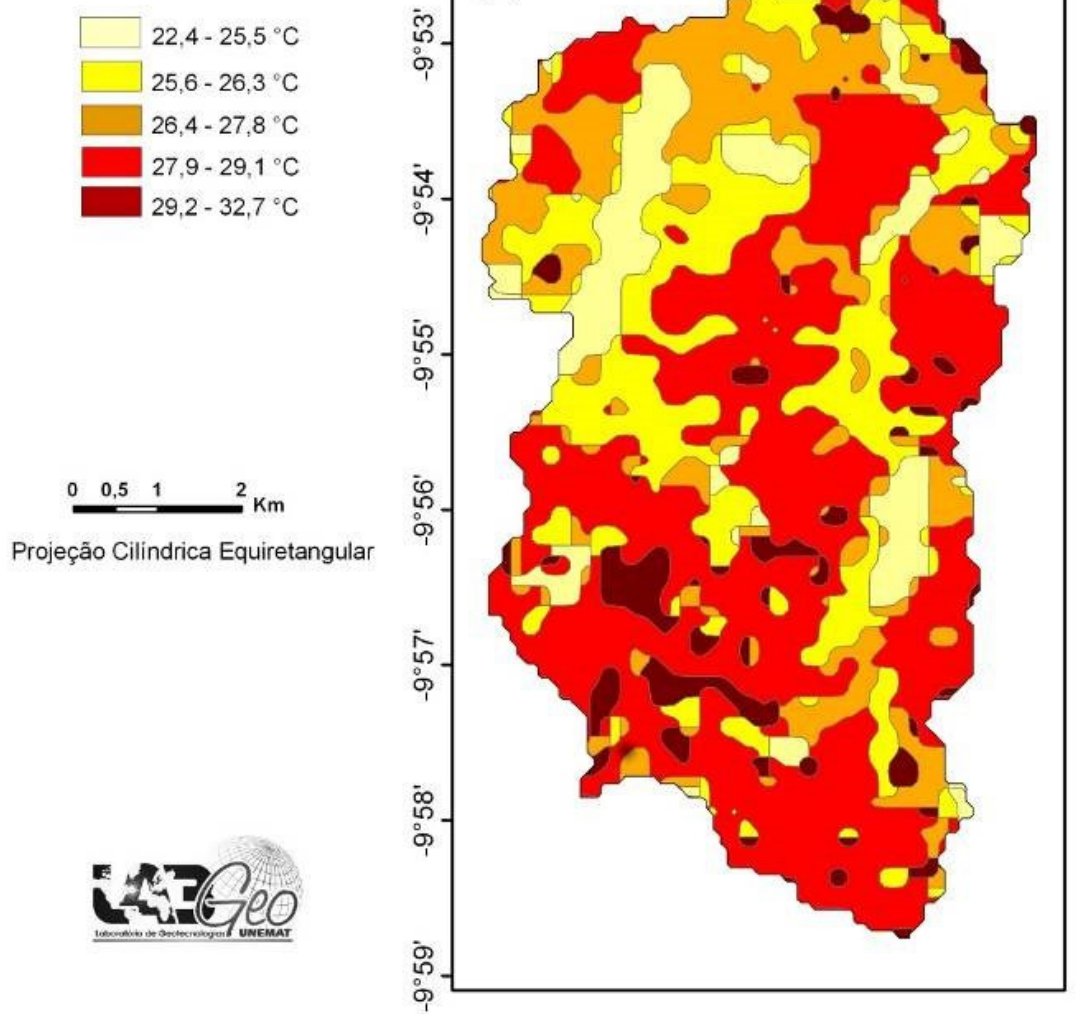

Fonte: autoria própria.

\section{Referências}

ALVARES, C.A.; STAPE, J.L.; SENTELHAS, P.C.; MORAES, G.; LEONARDO, J.; SPAROVEK, G. Köppen's climate classification map for Brazil. Meteorologische Zeitschrift, Oxford, v. 22, n. 6, p.711-728, 2013. https: //doi.org/10.1127/0941-2948/2013/0507.

ARAUJO, O.D.; BRUM, E.V.P.; SILVA, E.D.; CAIONI, C.; CLAUDINO, W.V. Acurácia posicional do modelo digital de terreno com os modelos digitais de elevação: ASTER GDEM, SRTM e TOPODATA. Enciclopédia Biosfera, Jandaia-GO, v.10, n.19, p. 42-51, 2014.

BECKER, B.K. Revisão das políticas de ocupação da Amazônia: é possível identificar modelos para projetar cenários? Parcerias Estratégicas, Brasília, n.12, p. 135159, 2001.

BLUNDEN, J.; ARNDT, D.S. State of the climate in 2011. Bulletin of the American Meteorological Society, Boston, v.93, n.7, p. S1-S282, 2012. https://doi .org/10. 1175/2012BAMSState of theClimate.
CAIONI, C.; NEVES, S.M.A.S.; CAIONI, S.; PARENTE, T.L.; RODRIGUES, B.P. Uso e ocupação da terra em áreas de preservação permanente no município Alta Floresta, Mato Grosso. Enciclopédia Biosfera, Jandaia-GO, v.14, n.25, p.1222-1230, 2017a. https://doi.org/10. 18677/EnciBio_2017A100.

CAIONI, C.; NEVES, S.M.A.S.; CAIONI, S.; BONINI, I.; PARENTE, T.L.; SILVA, A.C.S. Dinâmica da temperatura superficial da microbacia Pedra do Índio durante a seca de 2013. Revista Espacios, Montpellier, v.38, n.38, p. 09-20, $2017 b$.

CAIONI, C.; NEVES, S.M.A.S.; JUNIOR, S. S.; NEVES, R.J. Análise multitemporal da temperatura superficial do município de Carlinda-Mato Grosso. Boletim de Geografia, Maringá, v. 35, n. 3, p. 26-40, 2018. http: //dx.doi.org/10.4025/bolgeogr.v35i3. 27779.

CAIRES, S.M.; DÍAZ, J.G.C. Levantamento dos agrotóxicos usados por produtores rurais do município de Alta Floresta Mato Grosso. Revista de Biologia e Ciências da Terra, São Cristóvão-SE, v.2, n. 1, 2002. 
CALLEJAS, I.J.A.; DURANTE, L.C.; OLIVEIRA, A.S.; NOGUEIRA, M.C.J.A. Uso do solo e temperatura superficial em área urbana. Revista Mercator, Fortaleza, v. 10, n. 23, p. 207-223, 2011. https : //doi .org/10.4215/ RM0000.0000.0000.

CAMARGO, M.F.; ROQUE, C.G.; UMETSU, R.K.; PIERANGELI, M.A.; SILVA, T.R.C. Fertilidade do solo da área ciliar da sub-bacia hidrográfica Mariana, para fins de conservação ambiental. Revista Ambiente e Água, Taubaté, v. 5, n. 1, p. 57-67, 2010. https://doi.org/10.4136/ ambi-agua.119.

CÂMARA, G.; SOUZA R.C.M.; FREITAS, U.M.; GARRIDO, J. SPRING: Integrating remote sensing and GIS by object-oriented data modeling. Computers \& Graphics, New York, v.20, n.3, p. 395-403, 1996. https://doi. org/10.1016/0097-8493(96)00008-8.

COUTINHO, A.C.; ALMEIDA, C.; VENTURIERI, A.; ESQUERDO, J.C.D.M.; SILVA, M. Uso e cobertura da terra nas áreas desflorestadas da Amazônia Legal: TerraClass 2008. Brasília: Embrapa, Belém: INPE, 2013. 110 p.

CORRÊA, P.B; CORRÊA, J.A.J; ANDRADE, S.C.P. Análise da temperatura de superfície da área urbana de Santarém através de imagens termais do Landsat 5. Revista Geonorte, Manaus, v.2, n.4, p. 714-722, 2012.

ESRI. ArcGIS Desktop: release 9.2. Redlands: Environmental Systems Research Institute, 2007.

IBGE. Resultado do censo de 2010: Alta Floresta. Rio de Janeiro, 2010

IBGE. População do município de Alta Floresta. Disponível em: <https://sidra.ibge.gov.br>. Acesso em: 13 maio 2018.

LOARIE, S.R.; LOBELL, D.B.; ASNER, G.P.; MU, Q.; FIELD, C.B. Direct impacts on local climate of sugarcane expansion in Brazil. Nature Climate Change, London, v.1, n.2, p. 105-109, 2011. https://doi.org/10. 1038/nclimate1067.

MACEDO, M.N.; COE, M.T.; DEFRIES, R.; URIARTE, M.; BRANDO, P.M.; NEILL, C.; WALKER, W.S. Landuse-driven stream warming in southeastern Amazonia. Philosophical transactions of the Royal Society: biological sciences, London, v.368, n.1619, 2013. https : //doi.org/10.1098/rstb. 2012.0153.
MALARET, E.; BARTOLUCCI, L.A; LOZANO, D.F.; PATIL, E.A.; MCGILLEM, C.D. Landsat-4 and Landsat-5 Thematic Mapper data quality analysis. Photogrammetric Engineering and Remote Sensing, Falls Church, v.51, n.9, p. 1407-1416, 1985.

MATO GROSSO. Lei Complementar $\mathrm{N}^{\circ}$ 412, de 13 de dezembro de 2010. Dispõe sobre alterações na Lei Complementar no 38 , de 21 de novembro de 1995, na Lei Complementar $\mathrm{N}^{\mathrm{o}} 232$, de 21 de dezembro de 2005, Lei Complementar $\mathrm{N}^{\mathrm{o}} 233$, de 21 de dezembro de 2005, a Lei Complementar $\mathrm{N}^{0} 343$, de 24 de dezembro de 2008 e dá outras providências. Diário Oficial do Estado do Mato Grosso (DOEMT). Cuiabá,13 dez. 2010.

MOREIRA, M.A. (Ed.). Fundamentos do sensoriamento remoto e metodologias de aplicação. 2 ed. Viçosa, UFV, 2003. 307 p.

NASCIMENTO, F.M.; BARROS, Z.X.; BARROS, B.S.X.; CAMPOS, S.; RODRIGUES, J.G.L. Uso de SIG e fotografias aéreas na determinação de conflitos na rede de drenagem na Bacia Experimental do Rio Pardo. Irriga, v.17, n.3, p.346-352, 2012.

NERY, J.T.; CARFAN, A.C. Variabilidade da chuva na região Centro-Oeste do Brasil. Revista GeoPantanal, v. 07, n.17, p. 29, 2012.

NICHOL, J.E., High-Resolution sufarce temperature patterns related to urban morphology in a tropical city: a satellite-based study. Journal of Applied Meteorology, v.35, p.135-146, 1996. https://doi.org/10.1175/ $1520-0450(1996) 035<0135:$ HRSTPR $>2$. 0 . CO 2.

PRIMAVESI, O.; ARZABE, C.; PEDREIRA, M.S. $M u$ danças climáticas: visão tropical integrada das causas, dos impactos e de possíveis soluções para ambientes rurais ou urbanos. São Carlos: Embrapa Pecuária Sudeste, 2007. 200 p.

OLIVEIRA, A.S.; NOGUEIRA, M.C.D.J.A.; SANCHES, L.; NOGUEIRA, J.S. Variáveis meteorológicas e cobertura vegetal de espécies arbóreas em praças urbanas em Cuiabá, Brasil. Revista Brasileira de Meteorologia, v.28, n.4, p.389-400. 2013. http://dx.doi.org/10.1590/ S0102-77862013000400005.

ROSA, R. Geotecnologias na Geografia aplicada. Revista do Departamento de Geografia, v.16, n.1, p.8190, 2005. http://dx.doi.org/10.7154/RDG.2005. 0016.0009 
SILVA, J.W.F.; SANTOS, R.L. Estimativa da temperatura da superfície do solo de uma região semi-árida a partir do IRMSS (banda 4) do CBERS-2. In: Anais XIII Simpósio Brasileiro de Sensoriamento Remoto, Florianópolis, p. 1159-1166, 2007.

SILVÉRIO, D.V.; BRANDO, P.M.; MACEDO, M.N.; BECK, P.S.; BUSTAMANTE, M.; COE, M.T. Agricultural expansion dominates climate changes in southeastern Amazonia: the overlooked non-GHG forcing. Environmental Research Letters, v.10, n.10, p.104015, 2015. http: //dx.doi.10.1088/1748-9326/10/10/104015.

OMRAN, E.E. Detection of land-use and surface temperature change at different resolutions. Journal of Geographic Information System, v.4, n.03, p.189-203, 2012. http: //dx.doi .org/10.4236/jgis. 2012.43024.

RANDOW, C.; MANZI, A.O.; KRUIJT, B.; DE OLIVEIRA, P.J. ZANCHI, F.B.; SILVA, R.L.; CARDOSO, F.L. Comparative measurements and seasonal variations in energy and carbon exchange over forest and pasture in South West Amazonia. Theoretical and Applied Climatology, v.78, n.1-3, p.5-26, 2004.

SOUZA, A.P., MOTA, L.L., ZAMADEI, T.; MARTIN, C.C.; ALMEIDA, F.T.; PAULINO, J. 2013. Classificação climática e balanço hídrico climatológico no estado de Mato Grosso. Nativa, v.1, n.1, p.34-43, 2013. http: // dx.doi .org/10.14583/2318-7670.v01n01a07

SOUZA, S.C; Desmatamento e Clima em Alta Floresta - Amazônia Mato-grossense. Dissertação (Mestrado) Universidade Federal Mato Grosso. Programa de PósGraduação em Geografia Ambiente e Desenvolvimento Rural , Mato Grosso, 2006.

VOURLITIS, G.L; NOGUEIRA, J.S; LOBO, F.A.K.M; SENDALL, S.R; PAULO, C.A.A; DIAS, O.B; PINTO JR. ANDRADE, N.L.R. Energy balance and canopy conductance of a tropical semi-deciduous forest of the southern Amazon Basin. Water Resources Research, v.44, n.3, 2008. https://doi.org/10.1029/2006WR005526 